\title{
Is Cannabidiol the Cure-all Remedy we Have Been Looking for?
}

\author{
Leona Chang ${ }^{1}$ and Olga Ostrovsky ${ }^{2 *}$ \\ ${ }^{1}$ Department of Obstetrics and Gynecology, Cooper University Hospital, USA \\ ${ }^{2}$ Department of Surgery, Cooper Research Institute, USA
}

*Corresponding author: Olga Ostrovsky, Surgical Research, Department of Surgery, Cooper Research Institute, 401 Haddon Ave, Camden, NJ 08103, USA.

To Cite This Article: Olga Ostrovsky. Is Cannabidiol the Cure-all Remedy we Have Been Looking for?. Am J Biomed Sci \& Res. 2019 - 3(2). AJBSR. MS.ID.000645. DOI: 10.34297/AJBSR.2019.03.000645

Received: May 22, 2019 | Published: May 28, 2019

\section{Abstract}

Cannabidiol (CBD), the second major component of the plant Cannabis sativa, has become increasingly popular for its potential anxiolytic, antiinflammatory, antiemetic, and antipsychotic effects. It is non-psychotropic and has no abusive potential thus far, however scientific evidence on the pharmacological effects of CBD are limited to preclinical studies. More large and well-controlled clinical trials are needed to establish the clinical applications of CBD.

Cannabis sativa is one of three primary species from the Cannabaceae family, known for its cannabinoid extract, delta-9-tetrahydrocannabinol $(\triangle 9-\mathrm{THC}$ ). $\triangle 9$-THC is the most abundant component of Cannabis sativa and is popular for its psychoactive or euphoric effects. On the contrary, the second major component of the plant Cannabis sativa-cannabidiol (CBD)-does not have psychoactive effects; it has received the latest media buzz and marketing claims as a miracle cure for anxiety, depression, pain, inflammation, insomnia, and even cancer, without the high.

CBD can be derived from varieties of Cannabis, commonly referred to as hemp or marijuana. Hemp and marijuana differ by the amount of $\triangle 9$-THC in the plant. The Agriculture Improvement Act of 2018 (or 2018 Farm Bill) defines "hemp" as any part or derivative of the plant Cannabis sativa, with a $\triangle 9$-THC concentration of no more than $0.3 \%$ by dry weight, in contrast to up to $30 \%$ of $\Delta 9$-THC which is in marijuana [1]. The 100 -fold difference in the psychoactive component of Cannabis sativa is likely the growing public's interest in the potential therapeutic effects of CBD.

Products advertised to contain CBD have been increasingly found in oils, creams, cosmetics, gummies, and even dog treats. The increasing availability of cannabis-derived products is due to the passage of the 2018 Farm Bill which legalized hemp cultivation and declassified it as a Schedule I controlled substance. Now hemp-derived CBD is widely available in almost all 50 states. With the overwhelming ease in purchasing CBD products, what is the scientific evidence on CBD as a cure all drug and is it safe to use? There are a variety of pharmacologic effects of CBD reported in preclinical studies such as anxiolytic, anti-inflammatory, antiemetic, and antipsychotic properties (Figure 1).

\section{Figure 1: Pharmacologic effects of CBD [2].}

In vitro and In vivo research efforts have been growing to explore its effects in a wide range of diseases: Alzheimer's, Parkinson's, multiple sclerosis, epilepsy, Huntington's, hypoxic-ischemic injury, pain, anxiety, depression, cancer, nausea, inflammatory, auto-immune, cardiovascular, and diabetes [2]. For example, in an in vitro study of Alzheimer's disease with A $\beta$-stimulated PC12 neuronal cells, CBD inhibited hyperphosphorylation of tau protein and the formation of neurofibrillary tangles through the Wnt/ $\beta$-catenin pathway [3]. In a study of 21 patients with Parkinson's disease treated with either placebo, $75 \mathrm{mg}$ or $300 \mathrm{mg} /$ day CBD in a double-blind trial for 6 weeks, significant improvement of quality of life was seen with CBD $300 \mathrm{mg} /$ day compared to placebo [4]. CBD was also shown to inhibit breast cancer growth and metastasis through modulation of EGF/EGFR signaling pathway [5]. The only successful Phase III clinical trial thus far, has led to the U.S. Food and Drug Administration approval of Epidiolex (CBD 
oral solution) in 2018, for the treatment of two rare forms of epilepsy, Lennox-Gastaut syndrome and Dravet syndrome. Epidiolex has made headway as the first FDA-approved drug containing a purified drug substance derived from Cannabis sativa.

In addition to attempts on identifying therapeutic effects of CBD, its biosafety profile has been explored as early as in the 1970s. The World Health Organization states that CBD "exhibits no effects indicative of any abuse or dependence potential...to date, there is no evidence of recreational use of CBD or any public health related problems associate with use of pure CBD" [6]. In vivo studies have shown CBD in doses ranging 3-30 $\mathrm{mg} / \mathrm{kg}$ did not affect physiological parameters such as heart rate, blood pressure, body temperature; no effect was observed in motor function, gastrointestinal transit, or memory either [2,7]. Acute or chronic uses of CBD across different doses, whether oral (15-160 mg), inhalation (0.15 mg/ $\mathrm{kg}$ ), or intravenous injections (5-30 mg), did not induce side effects in human studies [7]. However, there are still other potential side effects of CBD observed in preclinical studies, such as drug interactions, immune modifications, and decreased receptor activity [7].

CBD is metabolized in the liver by the CYP3A4 enzyme, and in mice studies, has been shown to inactivate cytochrome P450 isozymes in the short term, while inducing them after repeated administration [8]. Many drugs undergo this hepatic metabolism, and thus raises the question whether CBD inhibits the metabolism of other drugs affecting changes in drug and CBD concentrations. This is especially important as many of the diseases which CBD claims to have an affect are managed by multiple pharmacologic agents. Though there are increasing preclinical studies identifying CBD's safety profile, many of the studies involve animals with different metabolic profiles between species, and the studies involve various doses of CBD across varying short-term periods. Due to the lack of concrete scientific evidence, the availability of CBD oil, granules, crystals, etc., is growing and becoming readily available on the market in doses ranging from $1 \mathrm{mg}$ to $1500 \mathrm{mg}$. These CBD products often contain unknown purity, variable and much lower doses than used in clinical trials with very limited instructions on usage. For example, a $10 \mathrm{ml}$ bottle of $3 \%$ CBD oil contains $1 \mathrm{mg}$ per drop (Table1).

Table 1: Overview of studies on CBD pharmacological effects [2].

\begin{tabular}{|c|c|c|}
\hline Disease & Effects & Refs \\
\hline Alzheimer's disease & $\begin{array}{l}\text { Antinflammutory, antioxidant, antiapoptotic in in vitro and in vivo models of } \\
\text { Ah-evoked neuroinflammatory and neurodegenerative responses. }\end{array}$ & $\begin{array}{l}\text { Hayakawa et al. (2007), Esposito et at. (2006a), Esposito et al. } \\
\text { (2006b), Martin-Moreno et al. (2011). Scuderi et al. (2014). } \\
\text { Cheng et at. (2014) }\end{array}$ \\
\hline Parkinson's disease & $\begin{array}{l}\text { Attenuation of the dopaminergic impairment in vivo; neuroprocection: } \\
\text { improvement of psychiatric rating and reduction of agitation nightmare and } \\
\text { ageressive behuviour in patients. }\end{array}$ & $\begin{array}{l}\text { Lastres-Becker et al. (2005), Zuardi et al. (2009), Chagas, Eckeli. } \\
\text { et al. (2014) }\end{array}$ \\
\hline Multiple sclerosis & $\begin{array}{l}\text { Improved signs of EAE in mice, antinflammatory and immunomodulatory } \\
\text { propertiex. }\end{array}$ & $\begin{array}{l}\text { Buccellato et at. (2011). Kozela et al. (2011. 2015). Mecha et al. } \\
\text { (2013), Giacoppo et al. (2015) }\end{array}$ \\
\hline Epilepsy & $\begin{array}{l}\text { Anticonvulunt in vitro and in vivo: reduced seizures frequency in children } \\
\text { and adults with treatment-resistant epilepsy. }\end{array}$ & Pertwee (2008), Devinsky et al. (2016) \\
\hline Huntington's disease & $\begin{array}{l}\text { Neuroprotective and antioxidant in mice transgenic models; no significant } \\
\text { Clinically important differences in patients. }\end{array}$ & fuvone et at. (2009), Sagredo et al. (2011), Consroe et al. (1991) \\
\hline Hypoxia-ischemia injury & $\begin{array}{l}\text { Short term neuroprotective effects; inhibition of excitotoxicity, oxidative } \\
\text { stress and inflammation in vitro and in rodent models. }\end{array}$ & $\begin{array}{l}\text { Pazos et al. (2012, 2013), Hayaknwa et al. (2007, 2009). } \\
\text { Valdepehlas et al. (2011) }\end{array}$ \\
\hline \multirow{2}{*}{ Pain } & $\begin{array}{l}\text { Analgesic effect in patients with neuropuchic pain resistant to ocher } \\
\text { treatments. }\end{array}$ & Petzke et al. (2016). Boychuk et al. (2015) \\
\hline & $\begin{array}{l}\text { Attenuation of the behavioural and glial chunges in animal models of } \\
\text { schizophrenia: anti-psychotic properties on ketamine-induced symptoms. }\end{array}$ & $\begin{array}{l}\text { Crippa et al. (2015), Gomes et al. (2015), Zuardi et al. (2006. } \\
\text { 2012) }\end{array}$ \\
\hline Anxiety & $\begin{array}{l}\text { Reduction of muscular tension, restiessness, fatigue, problems in } \\
\text { coencentration, improvement of social interactions in rodent models of anxiety } \\
\text { and stress: reduced social anxiety in putients. }\end{array}$ & $\begin{array}{l}\text { Lemos et al. (2010), Nmeida et al. (2013), Moreira et al. (2006), } \\
\text { de Mello Schier et al. (2014), Bergamaschi et at. (2011), Marinho } \\
\text { et al. (2015) }\end{array}$ \\
\hline Depeession & Anti-depressant effect in genetic rodent model of depression. & El-alfy et al. (2010). Hsiao et at. (2012), Shoval et al. (2016) \\
\hline Cancer & $\begin{array}{l}\text { Antiproliferative and anti-invasive actions in a large range of cancer types: } \\
\text { induction of autophagy-mediated cancer cell death; chemopreventive effects. }\end{array}$ & $\begin{array}{l}\text { Ligresti et al. (2006), McAllister et al. (2011), Shrivastava et at. } \\
\text { (2011), Pisanti et al. (2013), Rocha et at. (2014), Ramer et at. } \\
\text { (2014). Scott et al. (2014) }\end{array}$ \\
\hline Nausea & Suppression of nausea and conditioned gaping in rats & Parker et al. (2002), Rock et al. (2008) \\
\hline Inflammutory diseases & $\begin{array}{l}\text { Antinhammatory properties in several in vitro and in vivo models; inhibition } \\
\text { of inflammatory cytokines and pathways. }\end{array}$ & $\begin{array}{l}\text { Ribeiro et al. (2012, 2015), Kozela et al. (2010, 2011), Mecha } \\
\text { et at. (2012. 2013) }\end{array}$ \\
\hline Rheumutoid arthritis & Inhibition of TNF- $\alpha$ in an animal model & Malfait et al. $(2000)$ \\
\hline Infection & Activity zzainst methicillin-resistant Staphylococoss aurews & Appendino et at. (2008) \\
\hline $\begin{array}{l}\text { Inflammatory bowel and } \\
\text { Chron's diseases }\end{array}$ & \multirow{2}{*}{$\begin{array}{l}\text { Inhibition of macrophage recruitment and TNF-a secretion in vivo and } \\
\text { ex vivo; reduction in disease activity index in Chroe's patients. } \\
\text { Reduced infarct size through anti-oxidant and anti-inflammatory properties } \\
\text { in vitro and in vivo. }\end{array}$} & $\begin{array}{l}\text { Sucerdote et al. (2005), De filippis et at. (2011), Naftali et at. } \\
\text { (2011) }\end{array}$ \\
\hline Cardiowascular diseases & & Durst et at. (2007), Booz (2011), Stanley et at. (2013) \\
\hline Diabetic complications & Attenuation of fibrosis and myocardial dysfunction & $\begin{array}{l}\text { Weiss et al. (2006, 2008), Rajesh et al. (2010), Kosela et al. } \\
(2010)\end{array}$ \\
\hline
\end{tabular}

The previously mentioned Parkinson's study found $300 \mathrm{mg} /$ day to be an effective dose, which means a person would have to consume the entire bottle of CBD oil to achieve a therapeutic effect seen in the study. Since hemp-derived CBD is now legal but not well regulated, the development of CBD-based products for medical purposes has potential health dangers to users regarding the quality and purity of the product, effective doses, or route of administration of CBD for treatment of various diseases. Moreover, current commercially available CBD products are not regulated on its purity of CBD content. They may contain other cannabinoids (as there are hundreds of other chemical entities from the plant) that we do not yet know the full effects.

In order to maintain public safety within this booming industry, there is a strong need for adequate, long term, well-controlled clinical trials to better understand the biosafety profile and interactions of CBD. Evidence based therapeutic strategies could then be recommended for CBD dosage and administration for individual disease types. Preclinical studies have shown pharmacological potential and promise in CBD, but more large and robust clinical trials are needed to establish the clinical applications of CBD. 


\section{References}

1. Farm Bill (2018) Agriculture Improvement Act of 2018.

2. Pisanti S, Malfitano AM, Ciaglia E, Lamberti A, Ranieri R, et al. (2017) Cannabidiol: State of the art and new challenges for therapeutic applications. Pharmacol Ther 175: 133-150.

3. Esposito G, De Filippis D, Carnuccio R, Izzo A, Iuvone T (2006) The marijuana component cannabidiol inhibits $\beta$-amyloid-induced tau protein hyperphosphorylation through Wnt/ $\beta$-catenin pathway rescue in PC12 cells. J Mol Med 84(3): 253-258.

4. Chagas MHN, Zuardi AQ, Tumas V, Pena-Pereira MA, Sobreira ET, et al. (2014) Effects of cannabidiol in the treatment of patients with Parkinson's disease: an exploratory double-blind trial. J Psychopharmacol 28(11): 1088-1098.
5. Elbaz M, Nasser MW, Ravi J, Wani NA, Ahirwar DK, et al. (2015) Modulation of the tumor microenvironment and inhibition of EGF/EGFR pathway: Novel anti-tumor mechanisms of Cannabidiol in breast cancer. Mol Oncol 9(4): 906-919.

6. Cannabidiol Pre-Review Report (2017) Expert Committee on Drug Dependence $39^{\text {th }}$ Meeting. Geneva, p. 6-10.

7. Bergamaschi MM, Queiroz RH, Zuardi AW, Crippa JA (2011) Safety and side effects of cannabidiol, a Cannabis sativa constituent. Curr Drug Saf 6(4): 237-249.

8. Iffland K, Grotenhermen F (2017) An Update on Safety and Side Effects of Cannabidiol: A review of Clinical Data and Relevant Animal Studies. Cannabis Cannabinoid Res 2(1): 139-154. 